\title{
RELAÇÃO DO ESTADO NUTRICIONAL DE MINICEPAS COM O ENRAIZAMENTO DE MINIESTACAS DE EUCALIPTO $^{(1)}$
}

\author{
Ana Catarina Monteiro Carvalho Mori da Cunha ${ }^{(2)}$, Haroldo \\ Nogueira de Paiva ${ }^{(3)}$, Nairam Felix de Barros ${ }^{(4)}$, Helio Garcia Leite ${ }^{(3)}$ \\ \& Fernando Palha Leite ${ }^{(5)}$
}

\begin{abstract}
RESUMO
O enraizamento adventício de estacas é influenciado por fatores intrínsecos e extrínsecos do material vegetal, e o conhecimento da ação deles é fundamental para o sucesso da produção de mudas por miniestaquia. $O$ objetivo deste trabalho foi avaliar o grau de associação entre o estado nutricional das minicepas e o enraizamento de miniestacas de eucalipto, cultivadas em minijardim clonal em tubetes com subirrigação. Foram utilizados dados de enraizamento de miniestacas e teores de nutrientes quantificados pelas análises químicas dos tecidos foliares. A taxa de enraizamento foi correlacionada com o estado nutricional das brotações. Verificou-se que a nutrição mineral desempenha papel importante no enraizamento adventício de modo genótipo-dependente, ou seja, há diferença de comportamento dos clones em relação ao efeito dos nutrientes no enraizamento das miniestacas. Com relação ao teor de $\mathrm{K}$, Ca, $\mathrm{Mg}$ e $\mathrm{Mn}$, não foi observada associação com as taxas de enraizamento. Quanto aos demais nutrientes, em pelo menos um clone, houve associação positiva ou negativa entre as variáveis analisadas, com grau variável de acordo com o clone e o nutriente.
\end{abstract}

Termos de indexação: Propagação vegetativa, Eucalyptus, nutrição.

\footnotetext{
(1) Parte da dissertação de mestrado da primeira autora. Recebido para publicação em julho de 2007 e aprovado em março de 2009.

(2) Doutoranda do Programa de Pós-graduação em Ciência Florestal, Universidade Federal de Viçosa - UFV. Av. PH Rolfs s/n, CEP 36570-000 Viçosa (MG). E-mail: catarina_mori@yahoo.com.br

${ }^{(3)}$ Professor do Departamento de Engenharia Florestal, UFV. E-mails: hnpaiva@ufv.br, hgleite@ufv.br

(4) Professor do Departamento de solos, UFV. E-mail: nfbarros@ufv.br

(5) Pesquisador da Celulose Nipo-Brasileira S.A. - CENIBRA. Caixa Postal 100, CEP 35170-970 Ipatinga (MG). E-mail: fernando.leite@cenibra.com.br
} 


\title{
SUMMARY: RELATIONSHIP BETWEEN THE NUTRITIONAL STATUS OF MINISTUMPS TO THE ROOTING OF EUCALYPT MINICUTTINGS
}

\begin{abstract}
The adventitious rooting of cuttings is influenced by intrinsic and extrinsic factors of the plant material. The knowledge about the action mode of these factors upon rooting is fundamental for the successful production of clonal seedlings through minicuttings. The objective of this study was to evaluate the degree of association between the nutritional state of ministumps with the rooting of eucalypt minicuttings, grown in a clonal minigarden in tubes with subirrigation. Data from minicutting rooting and nutrient contents quantified by chemical analyses of the leaf tissues were used. The rooting rate was correlated with the nutritional status of the shoots. It was verified that mineral nutrition plays an important role in adventitious rooting in a genotype-dependent way, i.e, the performance of the clones differs in relation to the effect of nutrients on minicutting rooting. For potassium, calcium, magnesium and manganese no association was observed between nutrient contents and the shooting and the rooting rates. For the other nutrients, at least for one clone, there is a positive or negative association among the variables, and the degree of this association varies according to the clone and nutrient.
\end{abstract}

Index terms: vegetative propagation, Eucalyptus, nutrition.

\section{INTRODUÇÃO}

Florestas clonais de eucalipto permitem a preservação de genótipos de interesse econômico e resultam em plantios com melhor qualidade e homogeneidade (Assis et al., 2004). Nesse sentido, a propagação vegetativa vem sendo amplamente utilizada, pois possibilita a multiplicação de plantaselite obtidas em programas de cruzamento ou selecionadas em populações naturais (Schwambach et al., 2005).

O enraizamento adventício é uma etapa essencial na propagação vegetativa (De Klerk et al., 1999; Schwambach et al., 2005; De Smet et al., 2006), via miniestaquia, de espécies lenhosas economicamente importantes (Fett-Neto et al., 2001). Este é um processo complexo, alterado por diversos fatores: ambiente de propagação (Fett-Neto et al., 2001; Corrêa \& Fett-Neto, 2004; Corrêa et al., 2005); reguladores de crescimento (De Klerk et al., 1999; Wendling, 1999; Titon, 2001; Wendling \& Xavier, 2005; Fogaça \& FettNeto, 2005); nutrição mineral (Bellamine et al., 1998; Josten \& Kutschera, 1999; Schwambach et al., 2005; Francis \& Halford, 2006); características genéticas (Wendling \& Xavier, 2005); e juvenilidade dos propágulos (Wendling \& Xavier, 2005), sendo esses estudos importantes no sentido de estabelecer protocolos para a propagação clonal.

A importância de se conhecerem os fatores que alteram a formação de raízes está relacionada ao sucesso ou ao fracasso da produção de mudas via enraizamento adventício. Espécies lenhosas, mesmo in vitro, têm enraizamento genótipo-dependente. Diferentes espécies, híbridos, e diferentes clones do mesmo estoque parental podem requerer diferentes condições de cultivo (Mokotedi et al., 2000).
Dentre os fatores que afetam o enraizamento adventício, pode-se destacar a nutrição mineral. O estado nutricional da planta matriz que fornece os propágulos para o enraizamento é fator determinante do sucesso da propagação vegetativa, pois determinará a quantidade de carboidratos, auxinas, entre outros compostos metabólicos, fundamentais à indução e ao crescimento das raízes.

Malavasi (1994) afirma que há estreita relação entre a nutrição mineral e o enraizamento, no entanto a importância de vários nutrientes no processo ainda não está totalmente esclarecida. Para o autor, qualquer nutriente envolvido nos processos metabólicos associados à diferenciação e formação do sistema radicular é considerado essencial para a iniciação radicular.

Apesar de o enraizamento e a nutrição mineral estarem intimamente relacionados, poucos estudos têm sido conduzidos visando à caracterização dos efeitos de nutrientes específicos (Schwambach et al., 2005). Os maiores obstáculos ao conhecimento dos fenômenos envolvidos no processo de formação de raízes adventícias são relativos à dificuldade de isolar e caracterizar os fatores que os controlam, em virtude da complexidade e interação entre eles (Assis \& Teixeira, 1998).

De acordo com as informações disponíveis na literatura, os nutrientes influenciam de diferentes maneiras o enraizamento adventício. Nesse sentido, há também variações entre espécies quando se trata de um mesmo nutriente. Afetam negativamente a formação de raízes o $\mathrm{N}$ (Hartmann, 1997) em macieira (Fachinello et al., 1988) e videira (Haissig, 1986), e o Mg em Eucalyptus (Higashi et al., 2000). Já outros nutrientes, como Ca (Haissig, 1986; Bellamine et al., 1998), Zn (Hartmann, 1997) em Eucalyptus (Dell \& Wilson, 1985; Schwambach et al., 2005), Fe em 
seringueira (Tinley, 1961) e B (Malavasi, 1994) em Actidina deliciosa (Ono et al., 1998), Helianthus annus (Josten \& Kutschera,1999) e Eucalyptus globulus (Trindade \& Pais, 1997) influenciam positivamente esta variável. Com relação ao $\mathrm{Mn}$, os estudos remetem a informações contraditórias de acordo com a espécie estudada, sendo atribuída relação positiva em tomate (Marschner, 1995) e negativa em abacateiro (Reuveni \& Raviv, 1981). Com referência a K, Cu e S, os estudos são limitados, não se sabendo ao certo o efeito desses nutrientes no enraizamento adventício.

Apesar da importância da nutrição mineral no enraizamento adventício, há carência de informações sobre determinados nutrientes para o eucalipto. Há uma tabela com faixas de interpretação de nutrientes nas brotações, sendo esses valores adequados a algumas situações e clones comerciais, não podendo ser extrapolada a todos os materiais genéticos, nem a todos os nutrientes.

Diante do exposto, o objetivo deste trabalho foi avaliar o grau de associação entre o estado nutricional de minicepas e o enraizamento de miniestacas de eucalipto, cultivadas em minijardim clonal em tubetes com subirrigação.

\section{MATERIAIS E MÉTODOS}

Neste trabalho, foram utilizadas informações do banco de dados do viveiro da Celulose Nipo-Brasileira S.A. - CENIBRA, localizada no município de Belo Oriente - MG. Os dados utilizados foram referentes ao enraizamento das miniestacas e aos teores dos nutrientes quantificados pelas análises químicas do tecido foliar das minicepas oriundas do minijardim clonal em tubetes com subirrigação, sob abrigo de teto translúcido fixo.

O município de Belo Oriente - MG localiza-se na região do Vale do Rio Doce, com clima do tipo Aw, segundo a classificação de Köeppen (temperado chuvoso-mesotérmico), latitude de $19^{\circ} 18^{\prime} 23$ " S e longitude $42^{\circ} 22^{\prime} 46$ " W e $220 \mathrm{~m}$ de altitude. Apresenta precipitação média anual de $1.163 \mathrm{~mm}$; temperatura média anual de $25,2^{\circ} \mathrm{C}$, com máxima média de $31,5^{\circ} \mathrm{C}$, mínima média de $19,1^{\circ} \mathrm{C}$, e umidade relativa média de 65,2\% (Carneiro et al., 2008).

Os dados analisados foram referentes ao período de 2003 a 2005, incluindo os clones que continham maior quantidade de informações. Este número variou entres os clones devido à saída ou ao ingresso de determinado clone na linha de produção durante esse período. Os clones analisados foram: 57, $2719(E$. grandis $\mathrm{x}$ desconhecido); 129, 7074 (E. grandis); e 1046, 1213, 1274 (E. grandis $\mathrm{x}$ E. urophylla). Esses clones constituíam o minijardim clonal oriundo do enraizamento de miniestacas propagadas pelo método da estaquia convencional (Xavier \& Wendling, 1998).
Os dados utilizados nas análises estatísticas corresponderam aos índices de enraizamento (\%) média mensal em todo o período de estudo, e para aos teores dos nutrientes - média mensal em 2003 e 2004 e bimensal em 2005.

As mudas do minijardim apresentaram altura de aproximadamente $10 \mathrm{~cm}$ e foram dispostas em tubetes com capacidade de $50 \mathrm{~cm}^{3}$, sendo o substrato composto de partes iguais de vermiculita de granulometria grossa e casca de arroz carbonizada. A fertirrigação foi efetuada através de sistema automatizado, sendo usada a solução nutritiva apresentada no quadro 1.

Para minimizar a salinização, quinzenalmente foi aplicada uma lâmina de $10 \mathrm{~mm}$ de água pura, com valores de condutividade elétrica variando entre 0,06 e $0,14 \mathrm{mS} \mathrm{cm}^{-1}$ dependendo da época do ano, e a cada dois meses uma lâmina de água pura de $20 \mathrm{~mm}$. A solução nutritiva estoque apresentava a condutividade elétrica entre $1,0 \mathrm{e} 1,5 \mathrm{mS} \mathrm{cm}^{-1}$ durante os meses mais quentes do ano, e entre 1,5 e $2,0 \mathrm{mS} \mathrm{cm}^{-1}$ nos meses mais frios. Para todos os nutrientes, permitiu-se uma variação de concentração em torno de $10 \%$. O pH das soluções foi mantido entre 5,5 e 6,5.

A coleta das brotações para preparo das miniestacas foi feita de forma seletiva e contínua, de modo a manter as minicepas em bom estado vegetativo e com sistema radicular ativo. A periodicidade das coletas foi de aproximadamente uma por semana. As miniestacas apicais tinham tamanho variando entre 4 e $6 \mathrm{~cm}$, dois a três pares de folhas cortadas à metade visando minimizar perdas de água por transpiração.

Após serem coletadas e preparadas, as miniestacas foram colocadas em tubetes (com capacidade de $50 \mathrm{~cm}^{3}$ ) contendo um substrato composto de partes iguais de casca de arroz carbonizada e vermiculita de granulometria grossa. Neste substrato, foram adicionados $8,0 \mathrm{~kg} \mathrm{~m}^{-3}$ de superfosfato simples;

Quadro 1. Solução nutritiva estoque usada no minijardim clonal cultivado em tubete

\begin{tabular}{lr}
\hline Fertilizante & \multicolumn{1}{c}{ Dose } \\
& $\mathrm{g} 1000 \mathrm{~L}^{-1}$ \\
Nitrato de cálcio & $80.000,0$ \\
Sulfato de amônio & $27.800,0$ \\
Ácido fosfórico & $5.000,0$ \\
Cloreto de potássio & $20.000,0$ \\
Sulfato de magnésio & $14.400,0$ \\
Ácido bórico & 311,1 \\
Sulfato de zinco & 27,8 \\
Sulfato de cobre & 42,2 \\
Sulfato ferroso & $1.222,2$ \\
EDTA dissódico & $1.833,3$ \\
Sulfato de manganês & 666,7 \\
Molibdato de sódio & 11,1 \\
\hline
\end{tabular}


0,695 $\mathrm{kg} \mathrm{m}^{-3}$ de sulfato de amônio; 0,208 $\mathrm{kg} \mathrm{m}^{-3}$ de cloreto de $\mathrm{K} ; 0,014 \mathrm{~kg} \mathrm{~m}^{-3}$ de sulfato de $\mathrm{Zn} ; 0,014 \mathrm{~kg} \mathrm{~m}^{-3}$ de sulfato de $\mathrm{Cu} ; 0,014 \mathrm{~kg} \mathrm{~m}^{-3}$ de sulfato de $\mathrm{Mn}$; e $0,028 \mathrm{~kg} \mathrm{~m}^{-3}$ de ácido bórico.

Para o enraizamento, as miniestacas permaneceram em casa de vegetação (umidade relativa do ar $\geq 80 \%$ ) por 15 a 25 dias, seguindo, posteriormente, para a casa de sombra, com sombrite de $50 \%$, por cinco a sete dias. Na saída da casa de sombra, foi feita uma primeira seleção das mudas, separando-se as enraizadas das não enraizadas, agrupando-as por tamanho. Em seguida, foram dispostas em bandejas, de modo a preencher $30 \%$ de seus orifícios, e permaneceram em uma área de crescimento por 15 a 20 dias. Na saída dessa área, foi feita uma segunda seleção das mudas, com eliminação de brotações laterais, deixando-se apenas um caule. Posteriormente, as mudas passaram para área de aclimatação por 20 dias, até serem expedidas.

Para amostragem dos tecidos foliares, foram coletadas folhas totalmente expandidas no terço médio da minicepa em fase de produção, sendo lavadas com água destilada antes do processamento para análise. Foram coletadas duas amostras (constituídas de 10 minicepas) compostas para cada clone.

Após lavagem, as amostras foram colocadas em estufa para secagem a $60 \pm 5{ }^{\circ} \mathrm{C}$, até peso constante, e em seguida moídas. Foram determinados $\mathrm{Ca}, \mathrm{Mg}$, $\mathrm{K}, \mathrm{P}, \mathrm{S}, \mathrm{Zn}, \mathrm{Cu}, \mathrm{Fe}$ e Mn em extrato nitro-perclórico; $\mathrm{N}$ em extrato sulfúrico; e $\mathrm{B}$ em extrato de ácido clorídrico, após a calcinação, de acordo com metodologia descrita em Embrapa (1997).

Utilizou-se um critério temporal de modo que os dados coletados foram pareados mensalmente. Com os dados de enraizamento das miniestacas e análise química dos tecidos foliares, foram realizadas análises para estabelecer o tipo e o grau de associação linear entre as concentrações de macro e micronutrientes nas minicepas e a taxa de enraizamento das miniestacas. As hipóteses foram avaliadas pela estatística F nos níveis de significância de 5, 10 e $15 \%$.

No quadro 2 são apresentadas as concentrações de macro e micronutrientes consideradas adequadas, elevadas, baixas e deficientes para brotações de
Eucalyptus com idade entre 7 e 14 dias, em minijardim clonal. Esses valores foram usados para discutir os resultados encontrados.

\section{RESULTADOS E DISCUSSÃO}

Os números de miniestacas por minicepa encontrados neste trabalho foram superiores aos coletados na literatura (Quadro 3). Para Eucalyptus, as seguintes médias de produção são relatadas: 1,9 miniestaca no sistema de minijardim clonal em tubetes (sem subirrigação) a cada 20 dias (Wendling, 1999); 2,4 miniestacas por minicepa no sistema de minijardim clonal em tubetes com subirrigação a cada sete dias (Titon, 2001). Assim, constatou-se que os clones apresentaram comportamentos distintos em função da nutrição e da origem genética; todos os clones apresentaram produtividade satisfatória.

$\mathrm{O}$ coeficiente de correlação do $\mathrm{N}$ foi negativo para o clone 1213 (Quadro 3 e Figura 1a). Houve tendência de queda do índice de enraizamento quando os teores de $\mathrm{N}$ estavam acima do limite ou próximos do limite superior da faixa proposta por Higashi et al. (2004). A maioria dos índices de enraizamento ficou dentro dos níveis de $\mathrm{N}$ adequados (Quadro 2). Isso, de certa forma, explica a ausência de correlação, exceto para o clone 1213 , indicando que, de modo geral, o manejo do minijardim clonal em tubetes é satisfatório e que os clones apresentam comportamento distinto. Os resultados obtidos com o $\mathrm{N}$ no clone 1213 foram semelhantes aos obtidos na macieira (Fachinello et al., 1988) e na videira (Haissig, 1986), sendo referendados por Hartmann et al. (1997).

Foi observada correlação negativa do $\mathrm{P}$ no clone 1213 , mesmo com a média da concentração do nutriente dentro de nível adequado nas miniestacas (Quadro 3 e Figura 1b). Isso indica que o enraizamento desse clone pode ser favorecido com a redução da aplicação de $\mathrm{P}$ (Anuradha \& Marayanan, 1991). No entanto, o resultado deste estudo e o observado por esses autores são considerados exceções, pois, segundo Haissig (1974), a iniciação do primórdio radicular requer energia, que é proveniente dos processos de respiração, altamente dependentes de $\mathrm{P}$.

Quadro 2. Teores dos macro e micronutrientes considerados adequados, altos e baixos e deficientes para as brotações de Eucalyptus, com idade entre sete e 14 dias, em minijardim clonal (Higashi et al., 2004)

\begin{tabular}{|c|c|c|c|c|c|c|c|c|c|c|c|}
\hline \multirow{2}{*}{ Teor nutricional } & \multicolumn{11}{|c|}{ Nutriente } \\
\hline & $\mathbf{N}$ & $\mathbf{P}$ & $\mathbf{K}$ & $\mathbf{C a}$ & $\mathrm{Mg}$ & $\mathbf{S}$ & B & $\mathrm{Cu}$ & $\mathbf{F e}$ & Mn & $\mathrm{Zn}$ \\
\hline & & 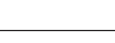 & $\mathrm{g} \mathrm{kg}^{-1}$ & & & - & - & & $\mathrm{mg} \mathrm{kg}^{-1}$ & & \\
\hline Alto & $>40$ & $>4$ & $>30$ & $>7$ & $>4$ & $>2,5$ & $>70$ & $>15$ & $>220$ & $>500$ & $>60$ \\
\hline Adequado & $28-40$ & $2,5-4$ & $15-30$ & $5-7$ & $2-3$ & $2-2,5$ & $35-70$ & $8-15$ & $100-220$ & $250-500$ & $30-60$ \\
\hline Baixo & $20-28$ & $1,5-2,5$ & $10-15$ & $3-5$ & $1-2$ & $1,3-2$ & $20-35$ & $5-8$ & $75-100$ & $150-250$ & $20-30$ \\
\hline Deficiente & $<20$ & $<1,5$ & $<10$ & $<3$ & $<1$ & $<1,3$ & $<20$ & $<5$ & $<75$ & $<150$ & $<20$ \\
\hline
\end{tabular}


Quanto ao K, não houve correlação entre as variáveis (Quadro 3). Isso pode ser explicado pelo fato de todos os clones apresentarem médias de concentração dentro de níveis considerados adequados (Quadros $2 \mathrm{e}$ 4). Esses resultados são semelhantes aos encontrados por Higashi et al. (2000) com Eucalyptus. Assim, para espécies do gênero Eucalyptus, as doses aplicadas nos sistemas de cultivo comerciais são adequadas.

$\mathrm{O}$ Ca é um dos principais nutrientes requeridos nos processos de divisão e elongação celular, no entanto não houve correlação significativa de enraizamento com o teor deste nutriente para nenhum dos clones (Quadro 3). Para a frequência de casos com concentração dentro da faixa de suficiência, observouse, de modo geral, equilíbrio entre os níveis adequado e alto (Quadro 5). Isso pode ser a causa da nãoconstatação de correlação entre as variáveis.

Não foi verificada correlação significativa em nenhum clone para $\mathrm{Mg}$ (Quadro 3). De acordo com a literatura, o papel do $\mathrm{Mg}$ durante a iniciação, o crescimento e o desenvolvimento radicular ainda não é claro. Foi observada grande frequência de casos dentro de níveis adequados (Quadro 5), o que pode explicar, de certa forma, a ausência de correlações, indicando que o manejo do minijardim está sendo realizado de maneira adequada.

Quadro 3. Coeficiente de correlação de Pearson entre as concentrações de nutrientes e onraizamento das miniestacas dos clones de Eucalyptus (Belo Oriente - MG, 2003 a 2005)

\begin{tabular}{|c|c|c|c|c|c|c|c|c|c|c|c|c|c|c|}
\hline \multirow{2}{*}{ Clone } & \multirow{2}{*}{$\begin{array}{c}\text { Média de } \\
\text { enraiza- } \\
\text { mento }\end{array}$} & \multirow{2}{*}{$\begin{array}{c}\mathrm{N}^{\circ} \mathrm{de} \\
\text { miniestacas } \\
\text { por mês }\end{array}$} & \multirow{2}{*}{$\begin{array}{l}\text { Número de } \\
\text { observação }\end{array}$} & \multicolumn{11}{|c|}{ Nutriente } \\
\hline & & & & $\mathbf{N}$ & $\mathbf{P}$ & $\mathbf{K}$ & $\mathbf{C a}$ & $\mathrm{Mg}$ & $\mathrm{S}$ & $\mathrm{Zn}$ & $\mathbf{C u}$ & $\mathrm{Fe}$ & Mn & $\bar{B}$ \\
\hline & $\%$ & & & & & & & & & & & & & \\
\hline 57 & 81,7 & 9,6 & 20 & 0,02 & 0,20 & 0,06 & 0,10 & 0,28 & $-0,15$ & $-0,14$ & $-0,16$ & $0,37^{\Delta}$ & 0,13 & $-0,06$ \\
\hline 129 & 86,5 & 11,6 & 18 & $-0,30$ & 0,01 & 0,14 & $-0,16$ & 0,12 & $-0,23$ & $-0,11$ & 0,17 & 0,34 & 0,32 & $-0,04$ \\
\hline 1046 & 71,9 & 10,4 & 23 & $-0,17$ & $-0,07$ & $-0,21$ & $-0,10$ & $-0,11$ & $-0,01$ & 0,05 & $-0,10$ & 0,27 & 0,12 & 0,15 \\
\hline 1213 & 76,5 & 12,4 & 20 & $-0,52^{*}$ & $-0,45^{*}$ & $-0,04$ & 0,04 & $-0,29$ & $-0,24$ & $-0,39^{\circ}$ & $-0,05$ & $0,38^{\Lambda}$ & $-0,21$ & $0,65^{*}$ \\
\hline 1274 & 76,4 & 12,4 & 18 & $-0,14$ & $-0,19$ & $-0,27$ & 0,04 & $-0,31$ & $-0,07$ & $-0,15$ & $-0,22$ & 0,26 & 0,35 & 0,18 \\
\hline 2719 & 86,5 & 13,2 & 26 & $-0,05$ & 0,12 & 0,16 & 0,13 & 0,12 & $-0,18$ & $-0,21$ & 0,09 & 0,10 & 0,01 & 0,20 \\
\hline 7074 & 79,0 & 12,8 & 28 & $-0,19$ & $-0,12$ & 0,16 & 0,22 & $-0,03$ & $-0,30^{\Delta}$ & $-0,09$ & $-0,30^{\Lambda}$ & $-0,05$ & $-0,02$ & $0,30^{\Lambda}$ \\
\hline
\end{tabular}

${ }^{*}$ : significativo a $5 \% ;^{\circ}$ : significativo a $10 \%{ }^{\circ}$ : significativo a $15 \%$.

Quadro 4. Médias das concentrações de macro e micronutrientes nas miniestacas dos clones de Eucalyptus (Belo Oriente - MG, 2003 a 2005), valores entre parênteses correspondem ao desvio-padrão

\begin{tabular}{|c|c|c|c|c|c|c|c|c|c|c|c|}
\hline \multirow{2}{*}{ Clone } & \multicolumn{11}{|c|}{ Nutriente } \\
\hline & $\mathbf{N}$ & $\mathbf{P}$ & $\mathbf{K}$ & $\mathbf{C a}$ & Mg & S & $\mathrm{Zn}$ & $\mathrm{Cu}$ & $\mathrm{Fe}$ & Mn & B \\
\hline & \multicolumn{6}{|c|}{$\mathrm{g} \mathrm{kg} \cdot 1^{-1}$} & \multicolumn{5}{|c|}{$-\mathrm{mg} \mathrm{kg}^{-1}$} \\
\hline 57 & $\begin{array}{l}35,7 \\
(3,1)\end{array}$ & $\begin{array}{r}3,4 \\
(0,4)\end{array}$ & $\begin{array}{l}24,8 \\
(4,1)\end{array}$ & $\begin{array}{c}8, \\
(1,7)\end{array}$ & $\begin{array}{r}3,0 \\
(0,6)\end{array}$ & $\begin{array}{r}1,3 \\
(0,5)\end{array}$ & $\begin{array}{l}29,0 \\
(5,7)\end{array}$ & $\begin{array}{l}11,3 \\
(1,7)\end{array}$ & $\begin{array}{l}115,3 \\
(65,1)\end{array}$ & $\begin{array}{r}646,5 \\
(210,3)\end{array}$ & $\begin{array}{r}80,1 \\
(22,9)\end{array}$ \\
\hline 129 & $\begin{array}{c}38,3 \\
(3,5)\end{array}$ & $\begin{array}{r}3,0 \\
(0,5)\end{array}$ & $\begin{array}{l}24,7 \\
(3,8)\end{array}$ & $\begin{array}{r}6,9 \\
(1,5)\end{array}$ & $\begin{array}{r}2,4 \\
(0,4)\end{array}$ & $\begin{array}{r}1,4 \\
(0,7)\end{array}$ & $\begin{array}{l}30,3 \\
(5,8)\end{array}$ & $\begin{array}{l}11,5 \\
(2,4)\end{array}$ & $\begin{array}{l}122,4 \\
(49,2)\end{array}$ & $\begin{array}{r}433,9 \\
(104,1)\end{array}$ & $\begin{array}{r}80,2 \\
(23,6)\end{array}$ \\
\hline 1046 & $\begin{array}{l}38,5 \\
(3,6)\end{array}$ & $\begin{array}{r}3,7 \\
(0,5)\end{array}$ & $\begin{array}{l}24,3 \\
(3,4)\end{array}$ & $\begin{array}{r}7,8 \\
(1,7)\end{array}$ & $\begin{array}{r}3,2 \\
(0,5)\end{array}$ & $\begin{array}{r}1,4 \\
(0,5)\end{array}$ & $\begin{array}{l}33,3 \\
(6,1)\end{array}$ & $\begin{array}{l}10,4 \\
(1,5)\end{array}$ & $\begin{array}{l}129,9 \\
(91,9)\end{array}$ & $\begin{array}{r}599,8 \\
(213,9)\end{array}$ & $\begin{array}{r}65,8 \\
(23,5)\end{array}$ \\
\hline 1213 & $\begin{array}{l}36,7 \\
(3,4)\end{array}$ & $\begin{array}{r}3,5 \\
(0,4)\end{array}$ & $\begin{array}{l}23,3 \\
(4,2)\end{array}$ & $\begin{array}{r}7,0 \\
(1,8)\end{array}$ & $\begin{array}{r}3,0 \\
(0,7)\end{array}$ & $\begin{array}{r}1,6 \\
(0,6)\end{array}$ & $\begin{array}{l}32,1 \\
(5,1)\end{array}$ & $\begin{array}{l}12,1 \\
(1,9)\end{array}$ & $\begin{array}{r}85,9 \\
(32,5)\end{array}$ & $\begin{array}{r}531,4 \\
(172,7)\end{array}$ & $\begin{array}{r}68,5 \\
(17,5)\end{array}$ \\
\hline 1274 & $\begin{array}{l}36,8 \\
(2,9)\end{array}$ & $\begin{array}{r}3,4 \\
(0,3)\end{array}$ & $\begin{array}{l}25,9 \\
(3,4)\end{array}$ & $\begin{array}{r}7,4 \\
(1,3)\end{array}$ & $\begin{array}{r}2,7 \\
(0,6)\end{array}$ & $\begin{array}{r}1,5 \\
(0,5)\end{array}$ & $\begin{array}{l}60,7 \\
(6,1)\end{array}$ & $\begin{array}{l}11,2 \\
(1,5)\end{array}$ & $\begin{array}{l}127,2 \\
(94,5)\end{array}$ & $\begin{array}{r}529,1 \\
(159,1)\end{array}$ & $\begin{array}{r}79,4 \\
(25,2)\end{array}$ \\
\hline 2719 & $\begin{array}{l}33,7 \\
(2,0)\end{array}$ & $\begin{array}{r}2,6 \\
(0,3)\end{array}$ & $\begin{array}{l}21,1 \\
(3,5)\end{array}$ & $\begin{array}{r}6,7 \\
(1,4)\end{array}$ & $\begin{array}{r}2,5 \\
(0,5)\end{array}$ & $\begin{array}{r}1,2 \\
(0,4)\end{array}$ & $\begin{array}{l}28,8 \\
(5,0)\end{array}$ & $\begin{array}{l}10,5 \\
(1,5)\end{array}$ & $\begin{array}{r}99,5 \\
(49,7)\end{array}$ & $\begin{array}{r}504,2 \\
(164,6)\end{array}$ & $\begin{array}{r}76,0 \\
(22,8)\end{array}$ \\
\hline 7074 & $\begin{array}{l}35,4 \\
(3,2)\end{array}$ & $\begin{array}{r}3,0 \\
(0,4)\end{array}$ & $\begin{array}{l}22,7 \\
(3,6)\end{array}$ & $\begin{array}{r}7,5 \\
(1,6)\end{array}$ & $\begin{array}{r}2,8 \\
(0,6)\end{array}$ & $\begin{array}{r}1,5 \\
(0,7)\end{array}$ & $\begin{array}{l}30,8 \\
(5,6)\end{array}$ & $\begin{array}{r}9,5 \\
(1,3)\end{array}$ & $\begin{array}{l}107,2 \\
(56,6)\end{array}$ & $\begin{array}{r}570,3 \\
(190,2)\end{array}$ & $\begin{array}{r}79,4 \\
(25,8)\end{array}$ \\
\hline
\end{tabular}


Para S, foi verificada correlação negativa significativa no clone 7074 (Figura 1c), que apresentou teor do nutriente nas brotações dentro de níveis considerados baixos (Quadros 2, 3 e 4). No quadro 5, observa-se que as concentrações de S estão, na maior parte, no limite entre deficiente e baixo em todos os clones. Isso pode ser indício de que o enraizamento do eucalipto é pouco afetado pelo $\mathrm{S}$ e que os limites de interpretação proposto por Higashi et al. (2004) precisam ser revistos.

Quanto ao Zn, foi observada correlação negativa para o clone 1213 , mesmo com a média de concentração dentro de níveis adequados (Quadros 3 e 4 e Figura 1d). No entanto, analisando a figura $1 \mathrm{~d}$, observa-se que apenas três pontos na parte inferior, do lado direito, foram responsáveis pela tendência de efeito negativo desse nutriente sobre o enraizamento do referido clone. Sem esses pontos, os dados se dispersariam, seguindo uma linha horizontal paralela ao eixo Y, indicando que o efeito do Zn, se houve, foi pequeno. Esperava-se encontrar correlações positivas para esse nutriente, tendo em vista sua atuação na síntese do triptofano, precursor natural do ácido indolacético, que, segundo Hartmann et al. (1997), é o principal hormônio responsável pelo enraizamento. Resultados contrários aos observados para o clone 1213 foram obtidos por Dell \& Wilson (1985) e Schwambach et al. (2005), também com espécies do gênero Eucalyptus.

Para o $\mathrm{Cu}$ foi observada correlação negativa no clone 7074 (Quadro 3 e Figura 1e). Para todos os clones, houve frequência de casos de concentração na faixa considerada adequada (Quadro 6). Isso pode explicar a ausência de correlações para a maioria dos clones, indicando que os teores desse nutriente que vêm sendo empregados são satisfatórios, exceto para o clone 7074, que possivelmente apresenta menor exigência em relação ao nutriente.

Para o Fe, observou-se efeito positivo entre as variáveis estudadas para os clones 57 (Figura 1f) e 1213 (Figura 1g), estando as concentrações do nutriente dentro de níveis adequados para o clone 57 e baixo para o clone 1213 (Quadros 3 e 4). Ainda verificou-se, de modo geral, grande dispersão na frequência de casos nas faixas de suficiência (Quadro 6), indicando a necessidade de mais estudos para adequar um protocolo eficiente de nutrição para o nutriente em questão. Esses resultados estão coerentes, pois, segundo Kirkby \& Romheld (2007), o Fe participa da biossíntese de enzimas com grupamento heme, como a peroxidase. Essa enzima

Quadro 5. Frequência de casos de concentração considerados alto (Al), adequado (Ad), baixo (B) e deficiente (D) para os macronutrientes nas miniestacas dos clones de Eucalyptus (Belo Oriente - MG, 2003 a 2005)

\begin{tabular}{|c|c|c|c|c|c|c|c|c|c|c|c|c|c|c|c|c|c|c|c|c|c|c|c|c|}
\hline \multirow{2}{*}{ Clone } & \multicolumn{4}{|c|}{$\mathbf{N}$} & \multicolumn{4}{|c|}{$\mathbf{P}$} & \multicolumn{4}{|c|}{$\mathbf{K}$} & \multicolumn{4}{|c|}{$\mathbf{C a}$} & \multicolumn{4}{|c|}{ Mg } & \multicolumn{4}{|c|}{$\mathbf{S}$} \\
\hline & $\mathrm{Al}$ & Ad & B & D & Al & Ad & B & D & $\mathrm{Al}$ & Ad & B & D & $\mathrm{Al}$ & Ad & B & D & Al & Ad & B & D & $\mathrm{Al}$ & Ad & B & D \\
\hline 57 & 0 & 20 & 0 & 0 & 2 & 18 & 0 & 0 & 2 & 16 & 2 & 0 & 17 & 3 & 0 & 0 & 2 & 18 & 0 & 0 & 1 & 1 & 6 & 12 \\
\hline 129 & 3 & 15 & 0 & 0 & 1 & 15 & 1 & 0 & 2 & 16 & 0 & 0 & 8 & 10 & 0 & 0 & 0 & 17 & 1 & 0 & 2 & 1 & 6 & 9 \\
\hline 1046 & 8 & 14 & 1 & 0 & 7 & 16 & 0 & 0 & 1 & 22 & 0 & 0 & 14 & 8 & 1 & 0 & 4 & 19 & 0 & 0 & 2 & 2 & 9 & 10 \\
\hline 1213 & 5 & 15 & 0 & 0 & 4 & 16 & 0 & 0 & 1 & 19 & 0 & 0 & 10 & 8 & 2 & 0 & 2 & 17 & 1 & 0 & 3 & 2 & 10 & 5 \\
\hline 1274 & 3 & 15 & 0 & 0 & 1 & 17 & 0 & 0 & 2 & 16 & 0 & 0 & 12 & 5 & 1 & 0 & 2 & 16 & 0 & 0 & 2 & 1 & 4 & 11 \\
\hline 2719 & 0 & 25 & 0 & 0 & 0 & 19 & 6 & 0 & 1 & 24 & 0 & 0 & 9 & 15 & 1 & 0 & 0 & 21 & 4 & 0 & 0 & 3 & 8 & 14 \\
\hline 7074 & 1 & 27 & 0 & 0 & 0 & 27 & 1 & 0 & 2 & 25 & 1 & 0 & 16 & 11 & 1 & 0 & 0 & 25 & 3 & 0 & 3 & 3 & 11 & 11 \\
\hline
\end{tabular}

Quadro 6. Frequência de casos de concentração considerados alto (Al), adequado (Ad), baixo (B) e deficiente (D) para os micronutrientes nas miniestacas dos clones de Eucalyptus (Belo Oriente - MG, 2003 a 2005)

\begin{tabular}{|c|c|c|c|c|c|c|c|c|c|c|c|c|c|c|c|c|c|c|c|c|}
\hline \multirow{2}{*}{ Clone } & \multicolumn{4}{|c|}{$\mathrm{Zn}$} & \multicolumn{4}{|c|}{$\mathrm{Cu}$} & \multicolumn{4}{|c|}{$\mathrm{Fe}$} & \multicolumn{4}{|c|}{ Mn } & \multicolumn{4}{|c|}{ B } \\
\hline & $\mathrm{Al}$ & Ad & B & D & Al & Ad & B & D & Al & Ad & B & D & $\mathrm{Al}$ & Ad & B & $\mathbf{D}$ & $\mathrm{Al}$ & Ad & B & D \\
\hline 57 & 0 & 8 & 11 & 1 & 0 & 19 & 1 & 0 & 2 & 7 & 6 & 5 & 5 & 15 & 0 & 0 & 15 & 4 & 0 & 1 \\
\hline 129 & 0 & 11 & 7 & 0 & 1 & 17 & 0 & 0 & 1 & 11 & 3 & 3 & 0 & 17 & 1 & 0 & 12 & 5 & 1 & 0 \\
\hline 1046 & 0 & 16 & 7 & 0 & 0 & 22 & 1 & 0 & 2 & 8 & 8 & 5 & 4 & 18 & 1 & 0 & 10 & 10 & 1 & 2 \\
\hline 1213 & 0 & 14 & 6 & 0 & 1 & 19 & 0 & 0 & 0 & 6 & 8 & 6 & 3 & 16 & 1 & 0 & 7 & 13 & 0 & 0 \\
\hline 1274 & 0 & 9 & 9 & 0 & 1 & 17 & 0 & 0 & 2 & 9 & 3 & 4 & 2 & 16 & 0 & 0 & 11 & 6 & 1 & 0 \\
\hline 2719 & 0 & 9 & 14 & 2 & 1 & 20 & 5 & 0 & 1 & 10 & 6 & 8 & 3 & 21 & 1 & 0 & 15 & 9 & 0 & 1 \\
\hline 7074 & 0 & 15 & 13 & 0 & 0 & 24 & 3 & 1 & 2 & 10 & 8 & 8 & 4 & 23 & 1 & 0 & 16 & 11 & 1 & 0 \\
\hline
\end{tabular}



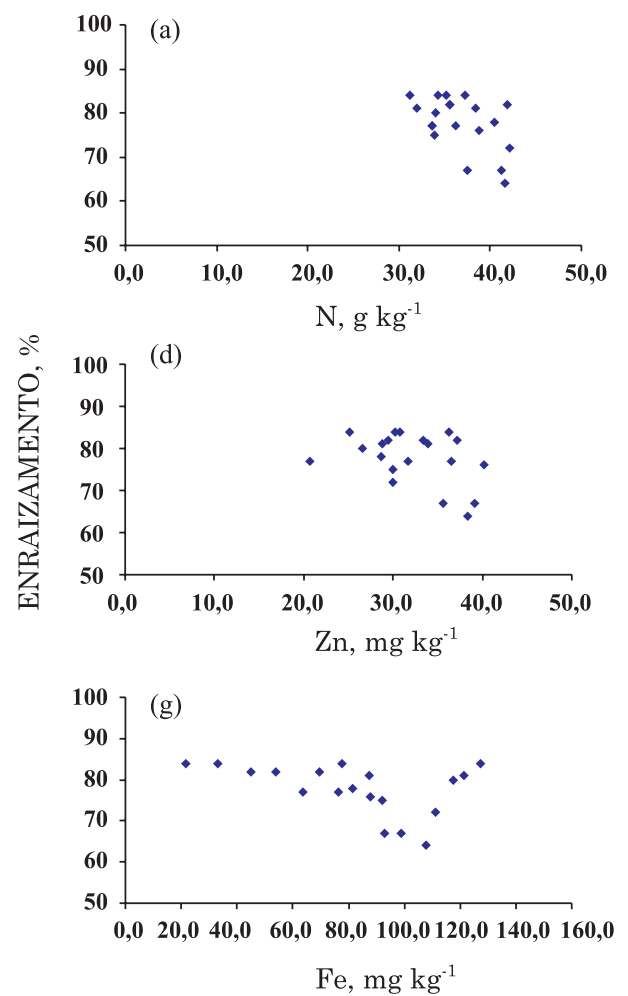
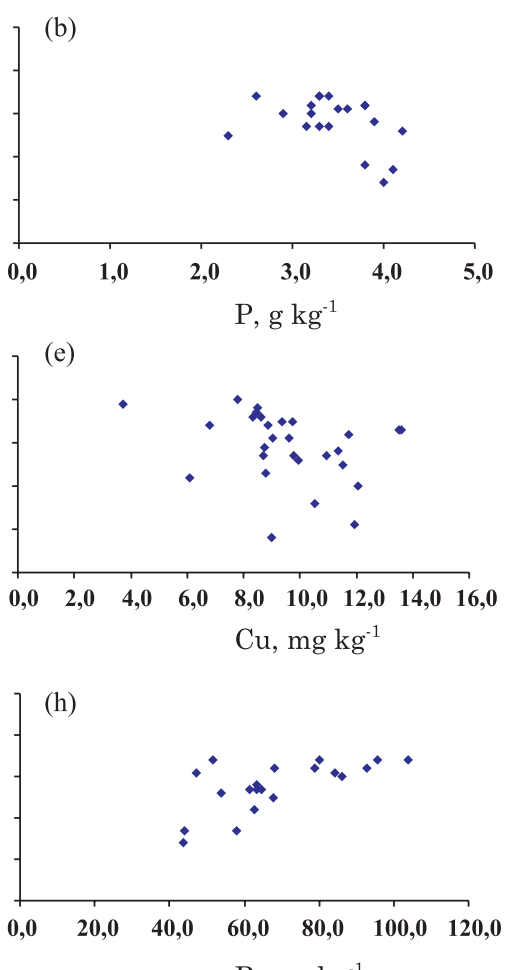
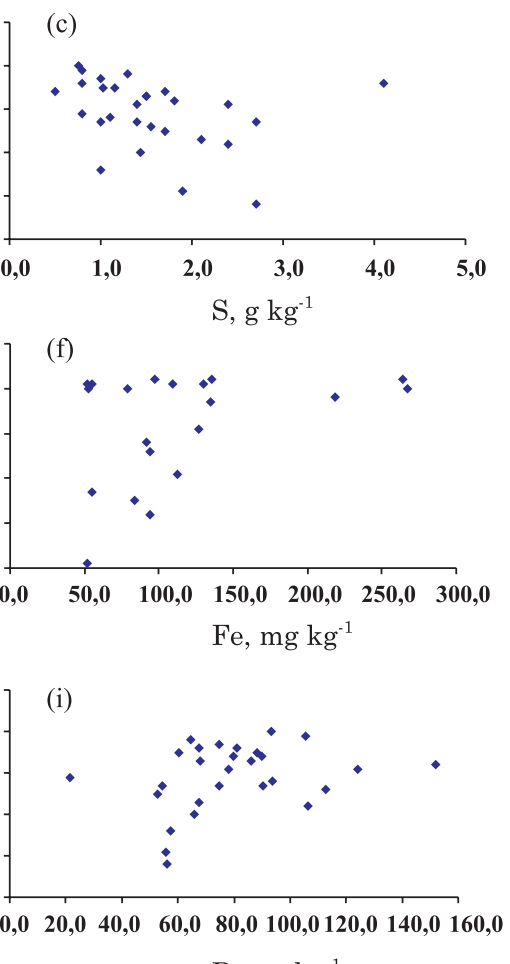

$\mathrm{B}, \mathrm{mg} \mathrm{kg}^{-1}$

Figura 1. Relação entre o índice de enraizamento e as concentrações de nutrientes nas miniestacas de Eucalyptus, para nitrogênio (a) e fósforo (b) no clone 1213, enxofre no clone 7074 (c), zinco no clone 1213 (d), Cu no clone 7074 (e), ferro nos clones 57 (f) e 1213 (g) e boro nos clones 1213 (h) e 7074 (i).

é importante na formação da parede celular e na lignificação, processos fundamentais na indução e no crescimento das raízes adventícias. Tinley (1961) encontrou resultados semelhantes trabalhando com a seringueira.

Não foi observada correlação para o Mn em nenhum dos clones (Quadro 3). Para a maioria dos casos, os teores de Mn nas brotações estavam dentro de níveis adequados (Quadro 6). Isso pode, de certa forma, explicar a ausência de correlação. Na literatura, os dados encontrados em relação a este nutriente são contraditórios. Marschner (1995) observou influência positiva do Mn sobre o enraizamento de tomate, estando de acordo com Kirkby \& Romheld (2007). Por outro lado, Reuveni \& Raviv (1981) verificaram efeito negativo no abacate, sendo referendado por Blazich (1987).

O B exerceu influência positiva nos clones 1213 (Figura 1h) e 7074 (Figura 1i) (Quadro 3). Isso indica que, possivelmente, esses clones apresentam maior exigência em relação ao B. Segundo Malavasi (1994), o B exerce efeito positivo no enraizamento por fazer parte da síntese de RNA e atuar no processo de divisão celular. Do ponto de vista fisiológico e bioquímico, a cadeia metabólica que envolve esse nutriente está ligada ao metabolismo, especialmente das auxinas, principal classe de hormônios envolvida no processo de enraizamento adventício (Lewis, 1980).
As brotações, depois de colhidas, permaneceram por quase 60 dias na casa de vegetação, casa de sombra, área de crescimento e área de aclimatação, onde enraizaram e cresceram em substrato adubado. A composição desse substrato pode interferir na qualidade do sistema radicular, por exemplo, aumentando o número e o comprimento de raízes finas. No entanto, a composição desse substrato não deve ter influenciado as taxas de enraizamento, pois, segundo Blazich (1987), a iniciação do primórdio radicular é influenciada primariamente pelos teores de nutrientes do tecido vegetal na base da estaca, sendo esses teores iniciais relacionados à nutrição da planta matriz em que a estaca foi coletada.

\section{AGRADECIMENTOS}

À Capes, pela bolsa de estudo; ao CNPq, pela bolsa de produtividade em pesquisa; e à Celulose NipoBrasileira S.A. - CENIBRA, pela concessão do banco de dados usados no trabalho.

\section{LITERATURA CITADA}

ANURADHA, M. \& NARAYANAN, A. Promotion of root elongation by phosphorus deficiency. Plant Soil, 136:273$275,1991$. 
ASSIS, T.F. \& TEIXEIRA, S.L. Enraizamento de plantas lenhosas. In: TORRES, A.C.; CALDAS, L.S. \& BUSO, J.A. Cultura de tecidos e transformação genética de plantas. Brasília, Empresa Brasileira de Pesquisa Agropecuária, 1998. v.1. p.261-296.

ASSIS, T.F.; FETT-NETO, A.G. \& ALFENAS, A.C. Current techniques and prospects for the clonal propagation of hardwood with emphasis on Eucalyptus. In: WALTER. C. \& CARSON, M. Plantation forest biotechnology for the $21^{\text {th }}$ century. New Delhi, Research Sign Post, 2004. v.1. p.303-333.

BELlAMINE, J.; PENEL, C.; GREPPIN, H. \& GASPAR, T. Confirmation of the role of auxin and calcium in the late phases of adventitious root formation. Plant Growth Reg., 26:191-194, 1998.

BLAZICH, F.A. Mineral nutrition and adventitious rooting. In: DAVIES, T.D.; HAISSIG, B.E. \& SANKHLA, N Adventitious root formation in cuttings. Portland, Dioscorides Press, 1987. p.61-69. (Advances in Plant Sciences Series, 2)

CARNEIRO, R.L.C.; RIBEIRO, A.; HUAMAN, C.A.M.; LEITE, F.P.; SEDIYAMA, G.C. \& BARROS, N.F. Consumo de água em plantios de eucalipto: Parte 1 Determinação da condutância estomática em tratamentos irrigado e nãoirrigado. R. Árvore, 32:1-10, 2008.

CORREAA, L.R. \& FETT-NETO, A.G. Effects of temperature on adventitious root development in microcuttings of Eucaltptus saligna Smith and Eucalytptus globulus Labill. J. Thermal Biol., 29:315-324, 2004.

CORRÊA, L.R.; PAIM, D.C.; SCHAWAMBACH, J. \& FETTNETO, A.G. Carbohydrates as regulatory factors on the rooting of Eucalyptus saligna Smith and Eucalyptus globulus Labill. Plant Growth Reg., 45: 63-73, 2005.

DE KLERK, G.J.; van der KRIEKEN, W. \& DE JONG, J.G. Review - The formation of adventitious roots: New concepts, new possibilities. In Vitro Cellular Develop. Biol. Plant, 35:189-199, 1999.

DE SMET, I.; VANNESTE, S.; INZÉ, D. \& BEECKMAN, T. Lateral root initiation or the birth of a new meristem. Plant Molec. Biol., 60:871-887, 2006.

DELL, B. \& WILSON, S.A. Effect of zinc supply on growth of three species of Eucalyptus seedlings and wheat. Plant Soil, 88:377-384, 1985.

EMPRESA BRASILEIRA DE PESQUISA AGROPECUÁRIA EMBRAPA. Serviço Nacional de Levantamento e Conservação de Solos. Manual de métodos de analise de solo. Rio de Janeiro, 1997. 212p.

FACHINELLO; J.C.; LUCCHESI, A.A. \& GUTIERREZ, L.E. Influência do anelamento na nutrição e o enraizamento de estacas lenhosas do porta-enxerto (Malling-Merton 106). Pesq. Agropec. Bras., 23:1025-1031, 1988.

FANG, W.C. \& KAO, C.H. Enhanced peroxidase activity in rice leaves in response to excess iron, copper and zinc. Plant Sci., 158:71-76, 2000.
FETT-NETO, A.G.; FETT, J.P.; GOULART, L.W.V.; PASQUALI, G.; TERMIGNONI, R.R. \& FERREIRA, A.G. Distinct effects of auxin and light on adventitious root development in Eucalyptus saligna and Eucalyptus globulus. Tree Physiol., 21:457-464, 2001.

FOGAÇA, C.M. \& FETT-NETO, A.G. Role of auxin and its modulators in the adventitious rooting of Eucalyptus species differing in recalcitrance. Plant Growth Reg., 45:1$10,2005$.

FRANCIS, D. \& HALFORD, N.G. Nutrient sensing in plant meristems. Plant Molec. Biol., 60:981-993, 2006.

HARTMANN, H.T.; KESTER, D.E.; DAVIES JUNIOR, F.T. \& GENEVE, R.L. Plant propagation: Principles and practices. 6.ed. New Jersey, Prentice-Hall, 1997. 770p.

HAISSIG, B.E. Metabolism during adventitious root primordium initiation and development. N. Z. J. For. Sci., 4:324-337, 1974.

HAISSIG, B.E. Metabolic processes in adventitious rooting of cuttings. In: JACKSON, M.B. New root formation in plants and cuttings. Dordrecht, Martinus Nijhoff, 1986. p.141-189.

HIGASHI, E.N.; SILVEIRA, R.L.V.A.; FIRME, D.J.; LEITE, F.P. \& GONÇALVES, A.N. Influência do estado nutricional da minitouça no enraizmento de miniestacas de Eucalyptus spp. In: REUNIÃO DE FERTILIDADE DO SOLO E NUTRIÇÃO DE PLANTAS, 25., Santa Maria, 2000. Anais... Santa Maria, SBCS/SBM, 2000. CD-ROOM.

HIGASHI, E.N.; SILVEIRA, R.L.V.A. \& GONÇALVES, A.N. Nutritional monitoring and fertilization in clonal macro, mini-, and microgardens. In: GONÇALVES, J.L.M. \& BENEDETI, V., eds. Forest nutrition and fertilization. Piracicaba, IPEF, 2004. p.195-221.

JOSTEN, P. \& KUTSCHERA, U. The micronutrient boron causes the development of adventitious roots in sunflower cuttings. Ann. Bot., 84:337-342, 1999.

KIRKBY, E.A. \& RÖMHELD, V. Micronutrientes na fisiologia de plantas: Funções absorção e mobilidade. Inf. Agron., 118:1-24, 2007.

LEWIS, D.H. Boron, lignification and the origin of vascular plants a unified hypothesis. New Phytol., 84:209-229, 1980.

MALAVASI, U.C. Macropropagação vegetativa de coníferas perspectivas biológicas e operacionais. Flor. Amb., 1:131$135,1994$.

MARSCHNER, H. Mineral nutrition of higher plants. London, Academic Press, 1995. 889p.

MOKOTEDI, M.E.O.; WATT, M.P.; PAMMENTER, N.W. \& BLAKEWAY, F.C. In vitro rooting and subsequent survival of two clones of cold-tolerant Eucalyptus grandis X Eucalyptus nitens Hybrid. HortScience, 35:1163-1165, 2000 .

ONO, E.O.; RODRIGUES, J.D. \& PINHO, S.Z. Efeito de auxinas e boro no enraizamento de estacas caulinares de Kiwi retiradas em diferentes épocas. Pesq. Agropec. Bras., 33:213-219, 1998 
REUVENI, O. \& RAVIV, M. Importance of leaf retention to rooting of avocado cuttings. J. Am. Soc. Hortic. Sci., 106:127-130, 1981.

SCHAWAMBACH, J.; FADANELLI, C. \& FETT-NETO, A.G. Mineral nutrition and adventitious rooting in microcuttings of Eucalyptus globulus. Tree Physiol., 25:487-494, 2005.

TINLEY, G.H. Effect of ferric dimethyldithiocarbamate on the rooting of cuttings of Hevea brasiliensis. Nature, 191:1217-1218, 1961.

TITON, M. Propagação clonal de Eucalyptus grandis por miniestaquia e microestaquia. Viçosa, MG, Universidade Federal de Viçosa, 2001. 65p. (Tese de Mestrado)
TRINDADE, H. \& PAIS, M.S. In vitro studies on Eucalyptus globulus rooting ability. In Vitro Cellular Develop. Biol. Plant, 33:1, 1997.

WENDLING, I. Propagação clonal de híbridos de Eucalyptus spp. por iniestaquia. Viçosa, MG, Universidade Federal de Viçosa, 1999. 70p. (Tese de Mestrado)

WENDLING, I. \& XAVIER, A. Influência do ácido indolbutírico e da miniestaquia seriada no enraizamento e vigor de miniestacas de clones de Eucalyptus grandis. R. Árvore, 29:921-930, 2005.

XAVIER, A. \& WENDLING, I. Miniestaquia na clonagem de Eucalyptus. Viçosa, MG, SIF, 1998. 10p. 
